\section{BMJ Paediatrics Open}

\title{
Pharmacotherapeutic management of paediatric heart failure and ACE-I use patterns: a European survey
}

Cristina Castro Díez, ${ }^{1}$ Feras Khalil, ${ }^{1}$ Holger Schwender, ${ }^{2}$ Michiel Dalinghaus, ${ }^{3}$ Ida Jovanovic, ${ }^{4}$ Nina Makowski, ${ }^{1}$ Christoph Male, ${ }^{5}$ Milica Bajcetic, ${ }^{6,7}$ Marijke van der Meulen, ${ }^{3}$ Saskia N de Wildt, ${ }^{8,9}$ László Ablonczy, ${ }^{10}$ András Szatmári, ${ }^{10}$ Ingrid Klingmann, ${ }^{11}$ Jennifer Walsh, ${ }^{12}$ Stephanie Läer ${ }^{1}$

\section{ABSTRACT}

To cite: Castro Díez C, Khalil F, Schwender $\mathrm{H}$, et al. Pharmacotherapeutic management of paediatric heart failure and ACE-I use patterns: a European survey. BMJ Paediatrics Open 2019;3:e000365. doi:10.1136/ bmjpo-2018-000365

- Additional material is published online only. To view please visit the journal online (http://dx.doi.org/10.1136/ bmjpo-2018-000365).

Received 1 September 2018 Revised 29 November 2018 Accepted 2 December 2018
Check for updates

(C) Author(s) (or their employer(s)) 2019. Re-use permitted under CC BY-NC. No commercial re-use. See rights and permissions. Published by BMJ

For numbered affiliations see end of article.

Correspondence to Dr Stephanie Läer; stephanie. laeer@uni-duesseldorf.de
Objective To characterise heart failure (HF) maintenance pharmacotherapy for children across Europe and investigate how angiotensin-converting enzyme inhibitors (ACE-I) are used in this setting.

Methods A Europe-wide web-based survey was conducted between January and May 2015 among European paediatricians dedicated to cardiology. Results Out of 200-eligible, 100 physicians representing 100 hospitals in 27 European countries participated. All participants reported prescribing ACE-I to treat dilated cardiomyopathy-related $\mathrm{HF}$ and $97 \%$ in the context of congenital heart defects; $87 \%$ for single ventricle physiology. Twenty-six per cent avoid ACE-I in newborns. Captopril was most frequently selected as first-choice for newborns (73\%) and infants and toddlers (66\%) and enalapril for children (56\%) and adolescents (58\%). Reported starting and maintenance doses varied widely. Up to $72 \%$ of participants follow formal creatinine increase limits for decision-making when up-titrating; however, heterogeneity in the cut-off points selected existed. ACE-I formulations prescribed by $47 \%$ of participants are obtained from more than a single source. Regarding symptomatic HF maintenance therapy, 25 different initial drug combinations were reported, although $79 \%$ select a regimen that includes ACE-I and diuretic (thiazide and/or loop), $61 \%$ ACE-I and aldosterone antagonist; $44 \%$ start with beta-blocker, $52 \%$ use beta-blockers as an add-on drug. Of the 89 participants that prescribe pharmacotherapy to asymptomatic patients, $40 \%$ do not use ACE-I monotherapy or ACE-I-beta-blocker two-drug only combination.

Conclusions Despite some reluctance to use them in newborns, ACE-I seem key in paediatric HF treatment strategies. Use in single ventricle patients seems frequent, in apparent contradiction with current paediatric evidence. Disparate dosage criteria and potential formulationinduced variability suggest significant differences may exist in the risk-benefit profile children are exposed to. No uniformity seems to exist in the drug regimens in use. The information collected provides relevant insight into real-life clinical practice and may facilitate research to identify the best therapeutic options for HF children.

\section{INTRODUCTION}

Despite its low incidence, paediatric heart failure $(\mathrm{HF})$ is an important public health
What is already known on this topic?

While the benefits of pharmacotherapy in adult heart failure (HF) are well established, efficacy in paediatrics has yet to be confirmed.

- Therapeutic strategies are largely based on the extrapolation of adult data and own experience. Little is known about drug treatment routines in everyday practice.

- Great uncertainty exists regarding optimal use of angiotensin-converting enzyme inhibitors (ACE-I) in HF children.

\section{What this study hopes to add?}

ACE-I are key in paediatric HF therapy, even for children with single ventricle physiology, in apparent contradiction with current paediatric evidence.

- Many physicians avoid using ACE-I in newborns and disparate usage criteria suggest significant differences may exist in the risk-benefit profile children are exposed to.

- No standardisation in dilated cardiomyopathy-related HF pharmacotherapy exists, and there appear to be marked deviations from conditions of use that current adult data support.

concern. ${ }^{1}$ It has been estimated that $10 \%-33 \%$ of all paediatric cardiac admissions are related to $\mathrm{HF}^{2}{ }^{2}$ Children whose hospitalisation is complicated by HF can have a $>20$-fold increase in the risk of death. ${ }^{4}$

Congenital heart defects (CHD) are responsible for most cases diagnosed in developed countries, although the majority are resolved with surgery. ${ }^{2}$ Dilated cardiomyopathies (DCM) are the main cause in patients with structurally normal hearts and account for $60 \%$ of paediatric cardiac transplants in Europe. ${ }^{235}$ Interest in drug therapy has increased with the goal of keeping 
patients stable until cardiac transplant or surgery can be performed and/or to delay or avoid the need. ${ }^{6}$

Beneficial effects of pharmacotherapy for adult HF are well established. Different neurohumoral antagonists have shown to impact the disease prognosis, among which angiotensin-converting enzyme inhibitors (ACE-I) are the only drugs recommended by both European and American adults HF guidelines for all patients. ${ }^{78}$ However, the efficacy of these medicines in children has yet to be confirmed. Evidence in paediatrics comes mainly from heterogeneous observational and small experimental studies, while the only two published large randomised controlled trials (RCT) failed to prove benefit. ${ }^{910}$ In the absence of conclusive data, paediatric therapeutic strategies are largely supported by adults' data extrapolation and own expertise. ${ }^{11} 12$ Commonly used drug treatment routines are mostly unknown.

ACE-I use may have become extensive in paediatric HF; however, unlike in adults, limited practical guidance exists to support the decision-making process associated with their clinical use. ${ }^{1113}$ Off-label prescribing, with its associated challenges and risks, ${ }^{14}$ is often needed. Little is known about how clinicians overcome this knowledge gap in everyday practice.

We conducted this study with the aims of characterising HF maintenance pharmacotherapy practices for children across Europe and enhancing understanding of the application of ACE-I in this condition. This might serve as a basis to determine priorities and facilitate future discussion and research to optimise the medical care provided to the paediatric HF population.

\section{METHODS}

\section{Overall study design}

A web-based survey type study design was selected to provide the best opportunity to collect information from a wide range of participants where resources of time, staff and budget were limited. Previous relevant surveys were reviewed and recommendations published in survey best practice guidelines followed. ${ }^{15-18}$ Thirteen experts supported the various steps of the study design. The process for the survey and survey instrument design and its distribution to participants is described in online supplementary figure S1.

Questionnaire topics were selected from the results of a literature review and expert group discussions. The survey was peer reviewed and pretested and pilottested by members of the expert panel and reliability and validity were assessed with positive results. ${ }^{15} 16$ The resulting questionnaire (online supplementary figure S2) explored usage patterns of ACE-I and drug therapy for DCM-related HF. Demographic questions about participants were also included.

\section{Study participants}

The target population was physicians providing paediatric cardiology care in hospitals across Europe (48 countries targeted), with the aim to have representation of each hospital. Since no official registries exist, a non-probability sampling design was deemed acceptable. ${ }^{15}$ Centres and physicians' contact data were identified through European and national paediatric cardiology association websites and presidents, hospital and cardiology conferences websites and LENA (https://www.lena-med.eu) consortium partners.

\section{Survey administration, data collection and statistical analysis} An invitation email, containing an individualised survey participation link, was sent to each clinician. Email and postal reminders were sent to non-respondents (online supplementary figure $\mathrm{S} 1$ ).

Data were collected between January and May 2015. To minimise errors during data processing, data extraction from the EvaSys web-survey platform and preparation of ready-to-analyse data was conducted by two researchers independently, and results were checked for consistency.

For the analysis of reported ACE-I doses in use, where a participant entered a starting dose range, the lower limit was considered. Where a participant entered a maintenance dose range, the median value was recorded for analysis. Answers were excluded from analysis if: (1) the exact requested information (starting dose in $\mathrm{mg}$ / $\mathrm{kg} /$ dose and maintenance dose in $\mathrm{mg} / \mathrm{kg} /$ day) was not provided, (2) target dose reported was smaller than starting dose or (3) the dose entered was considered not to be compatible with current knowledge ( $\geq 10$ times the larger doses reported in literature for children and/or adults).

Data analysis was performed using R V.3.2.1 and R-Studio V.099.465. Descriptive statistics were used. Association between variables was statistically tested using Fisher's exact test. Charts presented were created in Excel V.16.10.

\section{Ethics approval}

This study was conducted in compliance with the EU Data Protection Directive 95/46/EC and approved by the Heinrich-Heine-University Düsseldorf Institutional Ethics Committee and Data Protection Officer.

\section{Patient and public involvement}

No patients were involved.

\section{RESULTS}

Physicians representing 204 different hospitals in 39 countries were invited to participate, of whom 200 were considered for the analysis. The survey achieved an overall response rate of 50\% (100/200). Physicians from 27 different countries participated (figure 1). Most of them were working in a paediatric cardiology unit (91\%) with over 5 years work experience in this field $(96 \%)$ (online supplementary table S1). Seventy per cent of participants considered pharmacotherapy to have an impact of between 6 and 8 points out of 10 on the course 


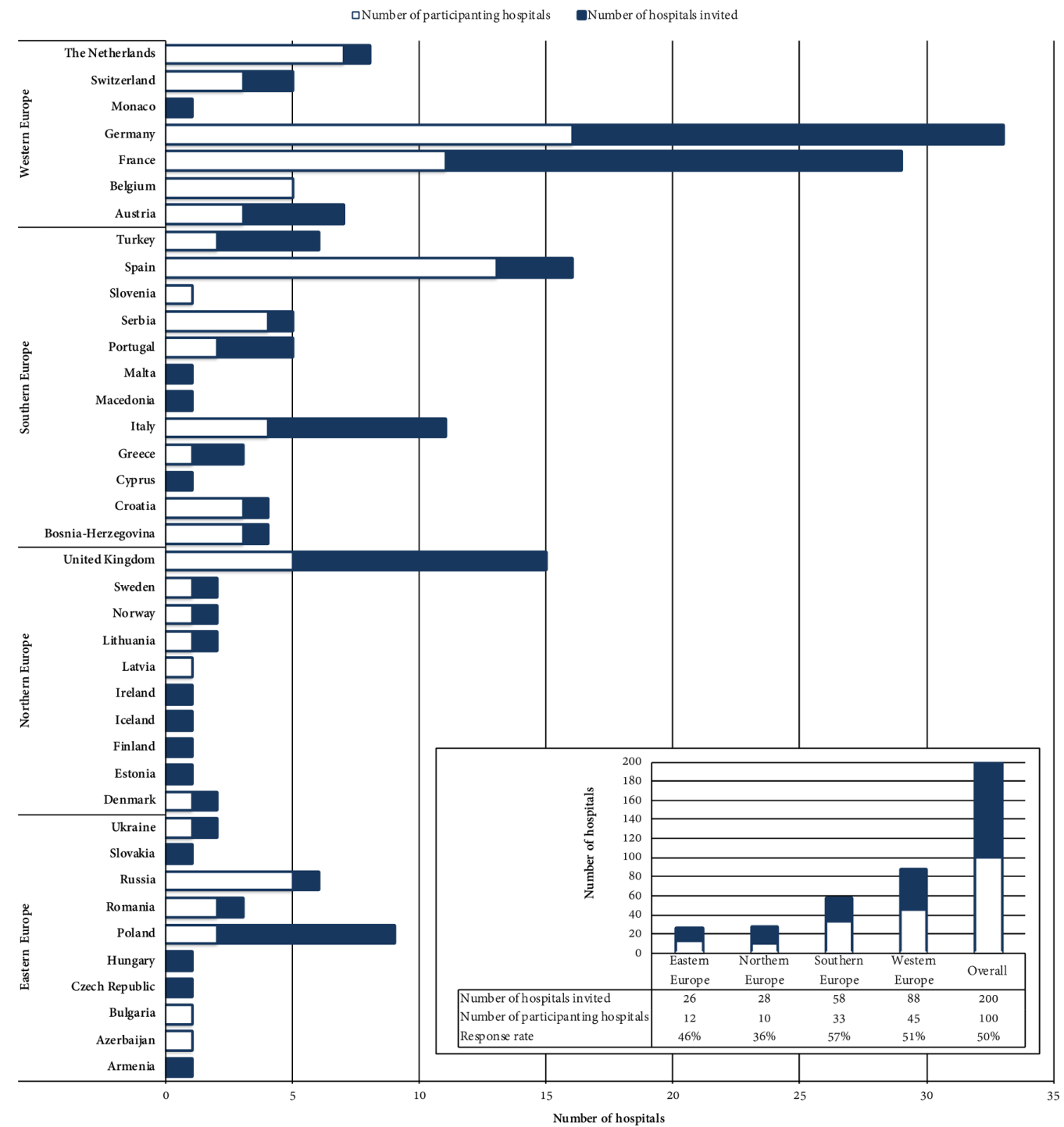

Figure 1 Survey participation/response rate by country and region. Hospitals were eligible if contact data of one clinician dedicated to the field of paediatric cardiology were available. We were able to find contact data of physicians from 204 different hospitals in 39 European countries. Four were excluded from analysis: one physician contacted expressed his wish not to participate, one did not feel able to participate because of limited experience, one was retired and one returned the completed questionnaire after the pre-established deadline. If more than one physician in a hospital answered, only the first questionnaire received was taken into consideration for analysis. Response rate was calculated as the number of different hospitals from which at least one physician submitted a completed or partially completed questionnaire divided by the number of different hospitals from which a physician was sent the invitation with questionnaire link. Criteria of the United Nations statistical division for Europe ${ }^{41}$ were followed for the classification of countries by European region. Four of the countries referred to are not considered as being European in this classification. Armenia and Azerbaijan were assigned here to Eastern Europe, Cyprus and Turkey to Southern Europe.

of the disease; $82 \%$ selected scores $\geq 6$ (online supplementary figure S3).

\section{ACE-I use in HF according to aetiology: DCM and CHD}

All participants reported using ACE-I therapy when DCM is the underlying cause of $\mathrm{HF}$ and $97 \%$ in the context of CHD (online supplementary table S2). Figure 2 shows the responses of the latter 97 participants on ACE-I use within four types of CHD according to HF symptomatic state. Eighty per cent reported using ACE-I in patients with CHD after heart surgery, the majority (64\%) for a period of between 1 and 6 months (online supplementary table S3).

\section{ACE-I use by age group}

ACE-I were reported to be used for the management of $\mathrm{HF}$ in all paediatric age groups, although $26 \%$ avoid using them in the newborn population (figure 3). No statistically significant association was found between the prescription of ACE-I to newborns and different variables related to the physicians or their working environment (online supplementary table S4). 
- Only asymptomatic patients $₫$ Only symptomatic patients $\backsim$ Both asymptomatic and symptomatic patients $\backsim$ None $\cdot$ No response

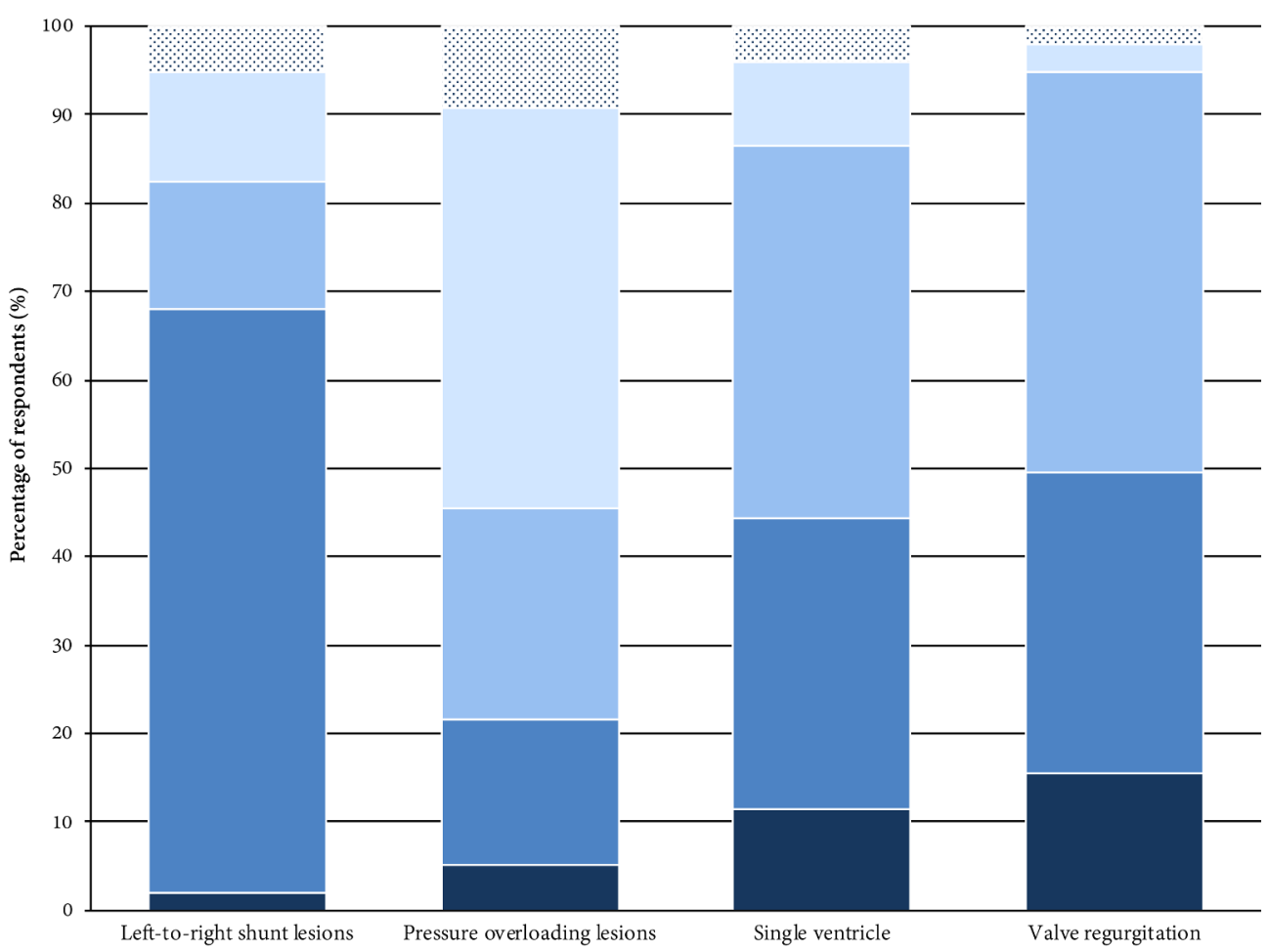

Type of congenital heart defect

Figure 2 ACE-I use for the management of congenital heart defects. This question was applicable to 97 participants $(n$ total for percentage calculation). Most of those 97 participants agreed on the usefulness of the therapy with ACE-I in patients with LRS lesions $(80 / 97=82 \%)$ single ventricle lesions $(84 / 97=87 \%)$ and/or valve regurgitation $(92 / 97=95 \%)$. A marked division of opinions existed among the physicians asked with regard to pressure overloading lesions ( $44 / 97=45 \%$ yes vs $51 \%$ no). Twelve participants reported using ACE-I for other CHD (mainly systemic right ventricle, Marfan syndrome, postsurgical correction of aortic coarctation, complex CHD). ACE-I, angiotensin-converting enzyme inhibitors; CHD, congenital heart defect; LRS, left-toright shunt.

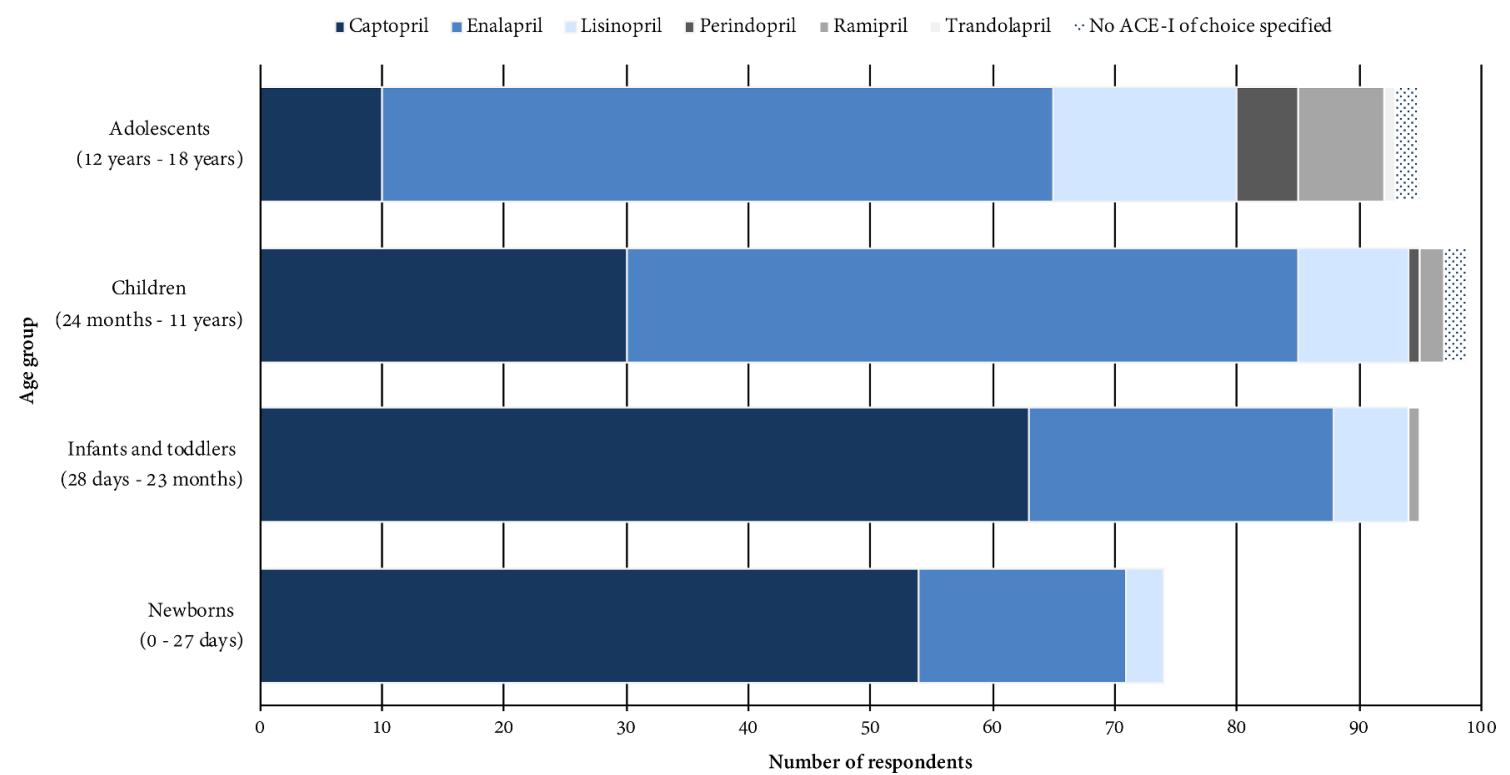

Figure 3 First-choice ACE-I by age group. Age groups were defined according to age classification for paediatric patients proposed by the EMA. ${ }^{42} 72 \%$ of the participants reported prescribing ACE-I in all age groups. ACE-I, angiotensin-converting enzyme inhibitor. 

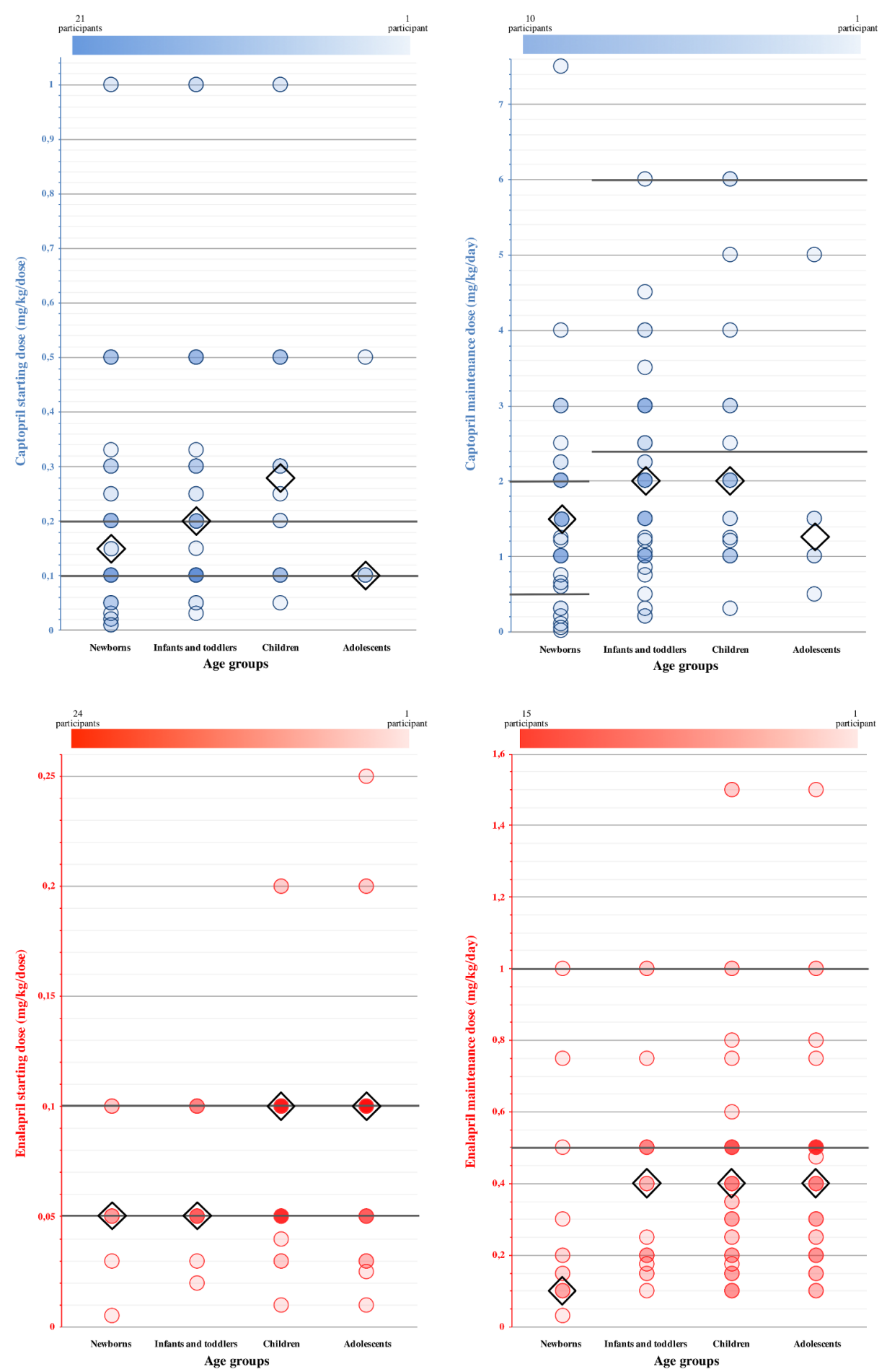

Figure 4 Starting dose (mg/kg/dose) and maintenance/target daily dose $(\mathrm{mg}(\mathrm{kg} /$ day) in use reported by survey participants for captopril and enalapril by age group. Opacity of each point is proportional to the number of participants that entered that dose. Diamonds $(\diamond)$ indicate median values. Thick horizontal lines indicate ranges of paediatric dosage recommendations that have been published. ${ }^{111327}$ Detailed results corresponding to these figures are provided in online supplementary tables S8 and S9. Age groups were defined as follows: newborns 0-27 days, infants and toddlers 28 days to 23 months, children 2-11 years and adolescents 12-18 years. ${ }^{42}$ Mean of starting doses reported for captopril was: $0.22 \mathrm{mg} / \mathrm{kg} / \mathrm{dose}$ for newborns, $0.26 \mathrm{mg} / \mathrm{kg} / \mathrm{dose}$ for infants and toddlers, $0.33 \mathrm{mg} / \mathrm{kg} / \mathrm{dose}$ for children and $0.18 \mathrm{mg} / \mathrm{kg} / \mathrm{dose}$ for adolescents. The mean of enalapril reported staring doses was: $0.06 \mathrm{mg} / \mathrm{kg} / \mathrm{dose}$ for newborns and infants and toddlers, $0.08 \mathrm{mg} / \mathrm{kg} / \mathrm{dose}$ for children and $0.09 \mathrm{mg} / \mathrm{kg} / \mathrm{dose}$ for adolescents. SD values are provided in online supplementary table S6. The reported captopril mean maintenance doses were 1.58, 1.99, 2.30 and $1.75 \mathrm{mg} / \mathrm{kg} /$ day for each age group, respectively, in order of increasing age. Mean of maintenance doses reported for enalapril was $0.27 \mathrm{mg} / \mathrm{kg} / \mathrm{day}$ for newborns and $0.41,0.42$ and $0.43 \mathrm{mg} / \mathrm{kg} / \mathrm{day}$ for infants and toddlers, children and adolescents, respectively. SD values are provided in online supplementary table S7. 

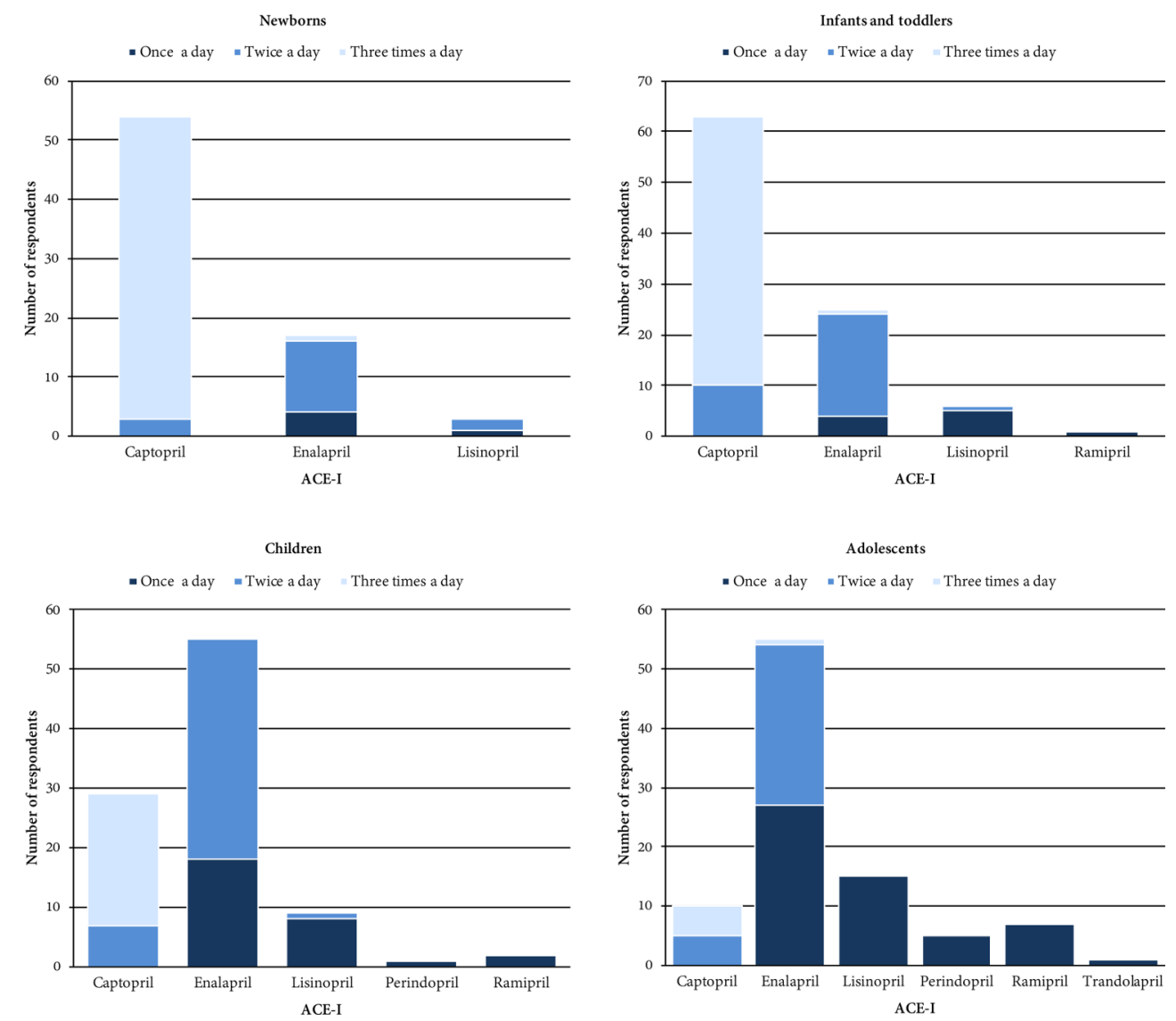

Figure 5 Dosing frequency of ACE-I maintenance dose reported for ACE-I of choice selected for each age group. Age groups were defined as follows: newborns 0-27 days, infants and toddlers 28 days to 23 months, children 2-11 years and adolescents 12-18 years. ${ }^{42}$ Captopril appeared to be most commonly prescribed three times per day and enalapril two times a day in all paediatric age groups except for adolescents. In this age group, the prevalence of prescribing enalapril once a day was similar to two times a day prescribing. Similarly, the percentage of clinicians reporting captopril administration two times and three times a day for adolescents was as high. Participants who reported using lisinopril, perindopril, ramipril and/or trandolapril prescribe these ACE-Is in single daily doses in virtually all cases. Answer option ' 4 times per day' was also provided, but this was not selected in any case. One of the 30 participants that reported using captopril for children did not specify any dosing frequency. ACE-I, angiotensin-converting enzyme inhibitor.

Of those participants using ACE-I within each age group, the majority selected captopril as the ACE-I of choice for newborns $(73 \%)$ and infants and toddlers $(66 \%)$, while enalapril was the most selected for children $(56 \%)$ and adolescents (58\%) (figure 3). Participants' main rationale for this choice is shown in online supplementary table S5.

\section{Dosage of first-choice ACE-I}

A wide range of starting $(\mathrm{mg} / \mathrm{kg} / \mathrm{dose})$ and maintenance doses $(\mathrm{mg} / \mathrm{kg} /$ day) were reported for each ACE-I and age group in virtually all cases. Results for the most commonly prescribed ACE-I, captopril and enalapril, are presented in figure 4. Summary statistics of all results is provided in online supplementary tables S6 and S7. Dosing frequencies reported for maintenance doses for each ACE-I within each age group are presented in figure 5 .

Division of opinions existed among the physicians surveyed on the best criterion that should be followed to establish the optimal ACE-I maintenance dose. In response to the question 'Do you increase the dose of ACE-I to your target, although patient has already improved with a lower dose?' Forty-five per cent of the participants answered 'No', 42\% 'Yes' and 13\% 'Sometimes'.

\section{ACE-I effectiveness and toxicity assessment}

All participants reported that they consider changes in signs and symptoms to assess the effectiveness of the ACE-I therapy. Ninety per cent rely on echocardiographic or radiographic parameters. Half of the physicians consider the level of natriuretic peptide and, similarly, $54 \%$ make use of clinical scores, $55 \%$ parents' perception and $55 \%$ the need for anticongestive medication. Only $15 \%$ reported applying quality of life scores.

In figure 6 , we display responses of participants on their attitude towards deterioration of renal function under ACE-I therapy in terms of serum creatinine increase. Regarding hypotension onset, $81 \%$ of participants reported basing the decision of stopping increasing the ACE-I dose on a defined criterion, while only $29 \%$ apply a 
- $1,1-1,4$ times $\backsim 1,5-1,9$ times $\backsim 2,0-2,9$ times $\backsim 3$ or more times $\quad$ No formal limits used $\because$ No response

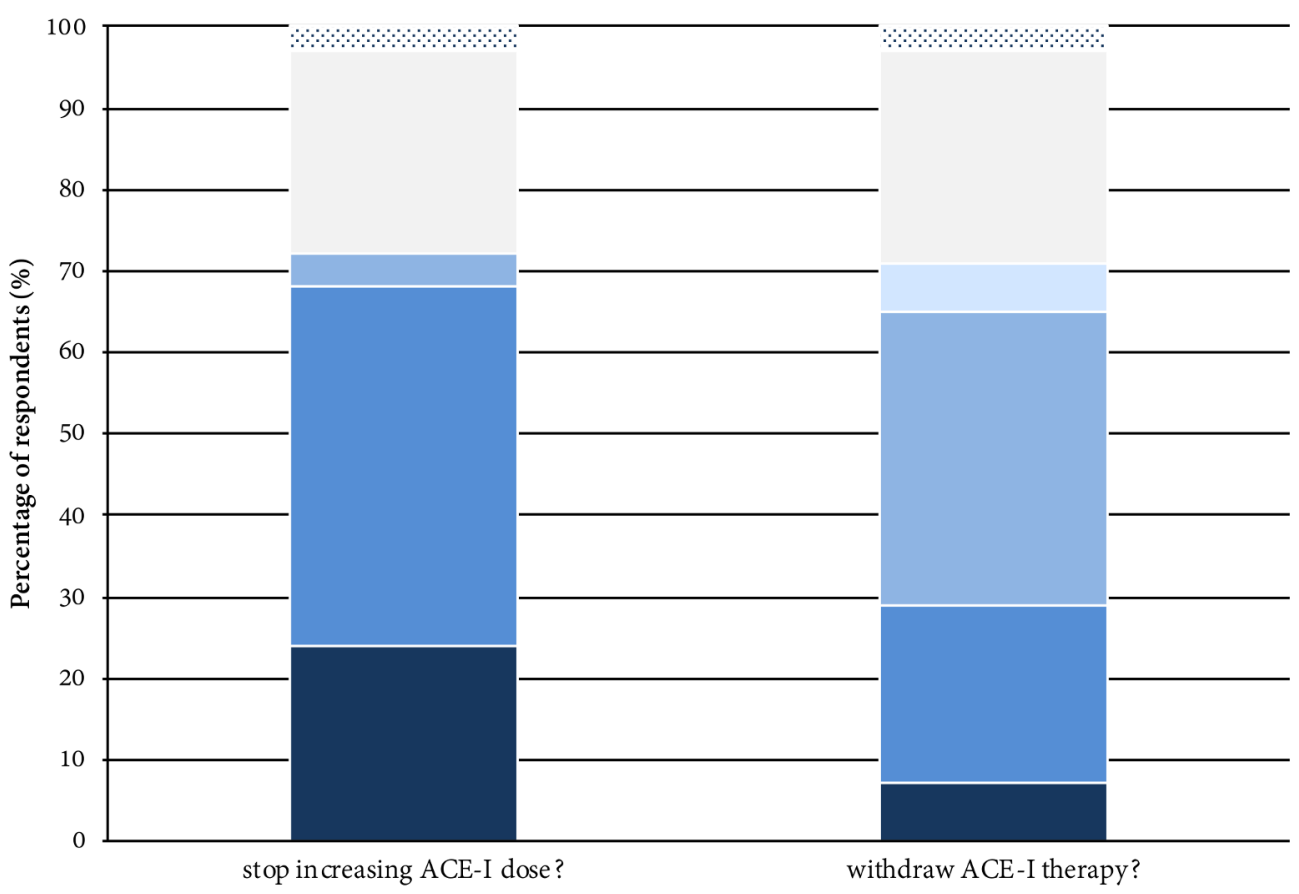

Which serum creatinine increase relative to baseline value makes you...

Figure 6 Attitude towards deterioration of renal function in terms of baseline serum creatinine level increase in the context of ACE-I therapy. The thresholds of baseline serum creatinine levels increase were based on the KDIGO proposed staging for acute kidney injury. ${ }^{43}$ Participants were requested to select the answer option that most reflected their practice. When considering deterioration of renal function in patients under ACE-I therapy, $25 \%$ of the participants claimed not to base treatment decisions on any formal cut-off value. A rise of 1.5 to 1.9-times in serum creatinine level was the most frequently selected limit as the criterion to stop increasing dose by those that reported being guided by formal limits $(61 \%, 44$ out of 72$)$, while an increase of 2.0-2.9 times creatinine was the most frequently selected option for therapy withdrawal (51\%, 36 out of 71). ACE-I, angiotensin-converting enzyme inhibitor.

criterion for therapy withdrawal. Most of them $(77 \%)$ use absolute blood pressure cut-off points according to age.

\section{ACE-I formulations}

Forty-seven per cent of the participants reported using liquid dosage forms, $44 \%$ capsules and $27 \%$ powder, when the adults' formulation is not suitable for a paediatric patient. Most of the physicians $(77 \%)$ selected a single type of formulation, but $47 \%$ indicated that they relied on more than one source (hospital pharmacy, community pharmacy, prepared by parents and/or others) to supply these formulations (online supplementary tables S10 and S11).

Drug regimens for the management of HF due to DCMsymptomatic patients

Table 1 provides participants' responses to questions regarding drugs introduced as initial therapy for patients with DCM HF who are not dependent on inotropic drugs, and medication introduced as add-on therapy where patients remain symptomatic.

Twenty-five different drug combinations were reported to be used for initial therapy (table 2). Seventy-nine per cent start treatment with a drug regimen that includes an ACE-I and a thiazide and/or loop diuretic, while $61 \%$ initiate treatment with a combination that includes an
ACE-I and an aldosterone antagonist and 53\% combine all three. Forty-four per cent of participants start with beta-blocker, while $52 \%$ use them as add-on therapy for patients that remain symptomatic. Fifty-four participants use cardiac glycosides, most of them (39) as add-on therapy.

Drug regimens for the management of $\mathrm{HF}$ due to $\mathrm{DCM}-$ asymptomatic patients

Most of the participants $(89 \%)$ consider pharmacological therapy for asymptomatic patients with DCM. Ninety-one per cent of them reported using ACE-I in this situation, with $29 \%$ as monotherapy. Twenty-nine per cent prescribe a two-drug only combination of ACE-I and beta-blocker. Detailed information is displayed in online supplementary tables S12 and S13.

\section{DISCUSSION}

This survey offers an overview of drug prescribing patterns for paediatric HF management across Europe and the criteria applied when using ACE-I to treat this condition. Eighty-two per cent of the participating physicians consider pharmacotherapy to have an impact $\geq 6$ 
Table 1 Report on drug use in maintenance therapy of symptomatic heart failure related to dilated cardiomyopathy

(1)

Initial therapy

Participants that gave duplicate

\begin{tabular}{|c|c|c|c|c|c|c|c|}
\hline & & & & & & & \\
\hline Drug class & n/total & $\%$ & $\mathrm{n} /$ total & $\%$ & $\mathrm{n}$ & n/total & $\%$ \\
\hline ACE-I & $96 / 100$ & 96 & $9 / 100$ & 9 & 5 & $100 / 100$ & 100 \\
\hline Angiotensin receptor blocker & $2 / 100$ & 2 & $8 / 100$ & 8 & 1 & $9 / 100$ & 9 \\
\hline Beta-blocker & $44 / 100$ & 44 & $52 / 100$ & 52 & 5 & $91 / 100$ & 91 \\
\hline Loop diuretic & $76 / 100$ & 76 & $19 / 100$ & 19 & 3 & $92 / 100$ & 92 \\
\hline Thiazide diuretic & $14 / 100$ & 14 & $21 / 100$ & 21 & 2 & $33 / 100$ & 33 \\
\hline Aldosterone antagonist & $65 / 100$ & 65 & $27 / 100$ & 27 & 4 & $88 / 100$ & 88 \\
\hline Cardiac glycoside & $16 / 100$ & 16 & $39 / 100$ & 39 & 1 & $54 / 100$ & 54 \\
\hline Other & $2 / 100$ & 2 & $6 / 100$ & 6 & 0 & - & - \\
\hline
\end{tabular}

The results corresponding to two multiple-choice questions are presented, one referring to initial therapy and one referring to add-on therapy prescribed for patients that remain symptomatic despite initial therapy. Some of the participants gave a duplicate answer, as they selected the same drug class in both questions (column 'Participants that gave a duplicate answer'). The total number of physicians that reported prescribing each drug class for the therapy of DCM-related symptomatic heart failure is presented under column 'overall total'.

Drugs reported under 'other' were acetylsalicylic acid and ivabradine for initial therapy and ivabradine and intravenous inotropics for add-on therapy.

ACE-I, angiotensin-converting enzyme inhibitors; DCM, dilated cardiomyopathy.

out of 10 points on the course of the disease, suggesting positive outcomes are being made in everyday practice.

\section{ACE-I use in paediatric HF: when?}

All survey participants agreed on their appropriateness for children with HF when DCM is the underlying cause. ACE-I-related benefits in humoral and haemodynamic parameters have been documented in DCM children, but, unlike in adults, only few improvements in clinical terms. ${ }^{19-22}$ However, it is widely accepted that 'DCM is the cause of paediatric HF that is most similar to that in adults ${ }^{23}$ and thus, the assumption that benefits of the same drug therapy also apply. Paediatric guidelines recommend using ACE-I in children with symptomatic and asymptomatic ventricular dysfunction. ${ }^{11} 12$ Our results suggest this is indeed an extended practice across Europe; all participants reported prescribing ACE-I for symptomatic patients with DCM, $96 \%$ as starting therapy. Of the physicians that treat asymptomatic patients, $91 \%$ rely on ACE-I.

Virtually all physicians (97\%) claimed to use ACE-I in the context of CHD. These children represent a highly heterogeneous group where the origin of HF is very often not limited to ventricular dysfunction, ${ }^{1}$ with the extrapolation of adult data becoming more complex. Our results suggest that European paediatricians believe that ACE-I plays an important role in the therapy of valve regurgitation, left-to-right shunt lesions, single ventricle physiology and in the postsurgical setting, for which $80 \%$ claimed to prescribe them. Regarding valve regurgitation, haemodynamic benefits have been described in small experimental studies that included only asymptomatic children. ${ }^{24}{ }^{25}$ However, most of the participants (77) considered symptomatic patients to also benefit from therapy. The $87 \%$ who reported prescribing ACE-I for single ventricle physiology patients is perhaps our most surprising finding. This appears to contrast with the conclusions of the authors of the only published large RCT in this patient group whose results did 'not support the routine use of enalapril'. ${ }^{9}$ A US Pediatric Heart Network survey revealed that, even though a significant change in clinical practice seemed to have occurred, 22\% of physicians consulted were not familiar with the results of this study and $28 \%$ of those who were aware did not change decisions accordingly, mainly due to disagreement with study design and interpretation of findings. ${ }^{26}$ These might have been also the reasons behind our study participants' responses. Overall, our observations suggest reliance on evidence in adults has a strong influence regarding decisions on ACE-I use in children with CHD.

Twenty-six per cent of physicians avoid using ACE-I in neonates. This is most likely due to potential variable responses to ACE-I in this age group together with low age and weight being recognised as key risk factors for renal failure in children on ACE-I. ${ }^{25} 2728$ Our finding highlights the need for guidance to allow optimal use of this drug class in the youngest population.

\section{ACE-I in paediatric HF: how?}

Our results suggest that captopril is the ACE-I of choice for newborns $(73 \%)$ and infants and toddlers $(66 \%)$, with enalapril for children $(56 \%)$ and adolescents $(58 \%)$. Long-acting ACE-I represent $30 \%$ of the first-choices reported for adolescents.

The range of starting and maintenance ACE-I doses reported was wide. Effective paediatric dosages have not yet been established and doses used in reported publications are varied.$^{25}$ Predominantly based on adults' data, starting with $0.05-0.1 \mathrm{mg} / \mathrm{kg} /$ dose and $0.1-0.2 \mathrm{mg} / \mathrm{kg} /$ dose for enalapril and captopril, respectively, has been 
Table 2 Drug regimens used as the initial maintenance therapy of symptomatic heart failure related to dilated cardiomyopathy

\begin{tabular}{|c|c|c|}
\hline Drug combinations & n/total & $\%$ \\
\hline \multicolumn{3}{|l|}{ Single-drug regimen } \\
\hline ACE-I & $5 / 100$ & 5 \\
\hline \multicolumn{3}{|l|}{ Two-drug regimen } \\
\hline ACE-I+Loop diuretic & $12 / 100$ & 12 \\
\hline ACE-I+Aldosterone antagonist & $1 / 100$ & 1 \\
\hline ACE-I+Beta-blocker & $4 / 100$ & 4 \\
\hline ACE-I+Thiazide diuretic & $1 / 100$ & 1 \\
\hline Aldosterone antagonist+Loop diuretic & $2 / 100$ & 2 \\
\hline \multicolumn{3}{|l|}{ Three-drug regimen } \\
\hline ACE-I+Aldosterone antagonist+Loop diuretic & $20 / 100$ & 20 \\
\hline ACE-I+Aldosterone antagonist+Beta-blocker & $4 / 100$ & 4 \\
\hline ACE-I+Aldosterone antagonist+Thiazide diuretic & $1 / 100$ & 1 \\
\hline ACE-I+Aldosterone antagonist+Cardiac glycoside & $3 / 100$ & 3 \\
\hline ACE-I+Betablocker+Loop diuretic & $7 / 100$ & 7 \\
\hline ACE-I+Betablocker+Thiazide diuretic & $1 / 100$ & 1 \\
\hline ACE-I+Cardiac glycoside+Loop diuretic & $4 / 100$ & 4 \\
\hline Aldosterone antagonist+Loop diuretic+Thiazide & $1 / 100$ & 1 \\
\hline \multicolumn{3}{|l|}{ Four-drug regimen } \\
\hline ACE-I+Aldosterone antagonist+Betablocker+Loop diuretic & $14 / 100$ & 14 \\
\hline ACE-I+Aldosterone antagonist+Betablocker+Thiazide diuretic & $4 / 100$ & 4 \\
\hline ACE-I+Aldosterone antagonist+Loop diuretic+Cardiac glycoside & $3 / 100$ & 3 \\
\hline ACE-I+Aldosterone antagonist+Loop diuretic+Thiazide diuretic & $1 / 100$ & 1 \\
\hline ACE-I+ARB + Loop diuretic+Cardiac glycoside & $1 / 100$ & 1 \\
\hline Aldosterone antagonist+Beta blocker+Cardiac glycoside+Loop diuretic & $1 / 100$ & 1 \\
\hline \multicolumn{3}{|l|}{ Five-drug regimen } \\
\hline ACE-I+Aldosterone antagonist+Beta blocker+Loop diuretic+Thiazide diuretic & $4 / 100$ & 4 \\
\hline ACE-I+Aldosterone antagonist+Betablocker+Cardiac glycoside+Loop diuretic & $3 / 100$ & 3 \\
\hline ACE-I+Aldosterone antagonist+Cardiac glycoside+Loop diuretic+Acetylsalicylic acid & $1 / 100$ & 1 \\
\hline ACE-I+Aldosterone antagonist+Beta blocker+Loop diuretic+Ivabradine & $1 / 100$ & 1 \\
\hline \multicolumn{3}{|l|}{ Six-drug regimen } \\
\hline ACE-I+Aldosterone antagonist+ARB + Beta-blocker+Loop diuretic+Thiazide diuretic & $1 / 100$ & 1 \\
\hline
\end{tabular}

Most of the participants start with $2(20 \%), 3(41 \%)$ or $4(24 \%)$ drugs in combination. One third of participants (34\%) reported starting with a drug combination that includes four or more drugs. Figures for the three drug regimens that were reported most frequently have been emphasised in bold.

ACE-I, angiotensin-converting enzyme inhibitors; ARB, angiotensin II receptor blockers.

recommended. ${ }^{11} 1327$ Participants' reports are largely in line with or above these ranges. The British National Formulary for children recommends starting with $0.01 \mathrm{mg} / \mathrm{kg}$ enalapril in neonates,${ }^{27}$ but our data suggest this conservative approach is not routine practice. In contrast, reported maintenance doses tend to be below recommendations (enalapril $0.5-1 \mathrm{mg} / \mathrm{kg} /$ day; captopril $0.5-2 \mathrm{mg} / \mathrm{kg} /$ day for neonates, $2.4-6 \mathrm{mg} / \mathrm{kg} /$ day for older age groups) except for captopril in newborns. ${ }^{11} 1327$ Evidence in adults indicates an apparent advantage of high versus low doses in terms of mortality and hospitalisations reduction. ${ }^{29}$ Therefore, our results suggest paediatric patients might be frequently receiving potentially suboptimal doses. Perhaps poor tolerance hinders achieving high ACE-I doses in HF children, ${ }^{9}$ but it is also possible that this is linked to the criterion followed to establish the optimal maintenance dose; $45 \%$ of participants reported they would stop uptitration once patient improvement had been observed. In adults, it appears the mechanisms that cause ACE-I long-term benefits are not relevant to symptom control, ${ }^{30}$ and hence, aiming towards the target doses selected in pivotal clinical trials, or failing this, towards the highest tolerated dose, is recommended. ${ }^{7}$ Considering an analogous approach for 
children would seem reasonable, but systematic data are needed to elucidate the best strategy.

The apparent lack of consistent and well-defined endpoints in reported paediatric HF studies represents a major obstacle in determining optimal dosing strategy. Our results may outline some opportunities for progress. Ninety per cent of participants reported using cardiac imaging to evaluate ACE-I therapy effectiveness, suggesting that standardising relevant measurements and quantification methods might bring substantial benefits. Only $54 \%$ of respondents translate clinical observations into HF scores. This may be another area of improvement since despite limitations, such scales are a means of facilitating communication in daily practice and research. ${ }^{31}$ Harmonising criteria to assess response to ACE-I therapy would enable the interpretation of published research and data sharing to evaluate therapy outcomes.

Similarly, disparity appeared to exist regarding the evaluation of ACE-I related adverse events. Deterioration of renal function and hypotension are those most commonly reported in children with HF, however, clear and consistent definitions, and standardised decision criteria for actions to be taken when these occur are lacking. ${ }^{32}$ No uniformity existed in the thresholds considered by participants to decide when to stop uptitration and/or withdraw ACE-I therapy if renal function deterioration was observed. Only $29 \%$ had a fixed criterion to withdraw therapy if hypotension occurs. Even though this topic is complex, and no clear relationship has been established between dose level and risk of adverse events, ${ }^{32}$ our results suggest it is likely that some patients are exposed to higher risks, while others might be deprived of potential benefits due to premature dose reduction or withdrawal.

A further challenge regarding dosing of ACE-I in paediatrics is the lack of authorised age-appropriate formulations licensed for use in paediatric HF throughout Europe. Our results imply that many patients could potentially be exposed to significant formulation-induced variability in dose since $47 \%$ of the respondents indicated that the ACE-I formulations they prescribe are provided by more than a single source, and $23 \%$ prescribe more than a single type of formulation. Studies in the UK and Ireland documented that ACE-I preparations used to overcome the lack of licensed medicines are heterogeneous and a variety of them with no proven bioequivalence are used interchangeably to treat HF children, ${ }^{33} 34$ which can lead to uncertainty in the dose level achieved. This may also be relevant to the interpretation, comparability and validity of ACE-I safety and efficacy published data, where information on the drug formulation and its administration is often omitted.

\section{Therapeutic schemes for HF due to DCM}

We focused on DCM-related HF to define a more homogeneous scenario. The 25 different drug combinations reported for initial therapy reflect a lack of uniformity. However, $79 \%$ of participants agreed on starting with a drug regimen that combines an ACE-I with loop and/or thiazide diuretic, in line with current paediatric guidelines. ${ }^{11} 12$ In contrast, a large percentage of the participants have a criterion on aldosterone antagonists use that differs from published recommendations, as $65 \%$ include them as starting therapy. Evidence in adults (no paediatric data exist) supports the use of low-dose aldosterone antagonists in patients that remain symptomatic despite initial therapy, to reduce mortality and hospitalisations. ${ }^{78}$ We can speculate that, rather than for their potential to influence prognosis, aldosterone antagonists are often introduced in paediatrics for their potassium sparing diuretic effect. However, it should be noted that Terano $e t a l^{35}$ found concomitant use of spironolactone to be an independent risk factor for acute kidney injury in HF children on ACE-I. Regarding beta-blockers, 91\% of participants prescribe them to treat symptomatic patients, but $52 \%$ reserve them for add-on therapy. In the only published large RCT on beta-blockers in paediatric HF, carvedilol did not significantly improve clinical outcomes. ${ }^{10}$ However, a recent Cochrane review concluded that despite insufficient evidence, existing data suggest that children with congestive HF might benefit from them. ${ }^{36}$ Paediatric guideline recommendations on beta-blocker use are less stringent. ${ }^{11} 12$ Our results seem to reflect a cautious attitude. Fifty-four participants reported using cardiac glycosides. Digoxin has historically been the mainstay of HF therapy, but no systematic data in children with structurally normal hearts have been published, and agreement currently exists on their only limited role in adults. Our results suggest there is still wide perception that they are of benefit.

Drug therapy for the management of asymptomatic DCM children also seems widespread (89\%). Since $83 \%-90 \%$ of children affected with DCM will develop HF, ${ }^{37}$ interventions with the aim of delaying/ preventing the worsening of the condition appears to be a particularly relevant topic. Universal agreement exists that all adults with asymptomatic left ventricular dysfunction should receive an ACE-I. ${ }^{78}$ Adding a betablocker concomitantly has proven beneficial, although advantages in adults without a history of myocardial infarction are less clear. ${ }^{78}$ Twenty-nine per cent of these paediatricians reported prescribing ACE-I monotherapy in this scenario and 29\% a two-drug only combination of ACE-I and beta-blocker. While this might be justified by extrapolation from adults, the remaining $42 \%$ of physicians decide on a drug regimen that appears not to be supported by any evidence.

\section{Limitations}

Our results are constrained by the reliance on self-reported clinicians' practice. ${ }^{39}$ We were not able to enrol a statistically representative sample and responses of an individual physician cannot be assumed to be consistent with practice of others from the same institution. Thus, our findings may not be extrapolated to standard European clinical practice. However, population characteristics 
indicate that a comprehensive picture of the current state of $\mathrm{HF}$ treatment routines has been provided.

Several factors favour the quality of our study. Survey instrument development included the recruitment of a supporting expert panel, pretesting and pilot-testing, reliability and validity testing with positive results, and a statistical analysis manual was elaborated for the processing and analysis of data. ${ }^{1516}$

\section{Conclusion}

Despite some reluctance to their use in newborns, large reliance on ACE-I therapy for HF children seems to exist among European paediatricians. The apparent discrepancy between our observations and the conclusions of the Infant Single Ventricle trial is remarkable. ${ }^{9}$ Heterogeneity in ACE-I usage criteria and potential formulation-induced variability suggest that significant differences may exist in the risk-benefit profile children are exposed to, clearly showing that the collation and evaluation of systematic data should be a priority. Meanwhile, utilisation of best knowledge available should be maximised to seek agreement and reduce unjustified variability.

No uniformity in the drug combinations selected for DCM-related HF therapy exists. We observed common trends consistent with adults' evidence as well as marked deviations: frequent use of aldosterone antagonists as initial therapy and observations regarding asymptomatic patients.

Established prescribing practices play a critical role in the viability of further research. ${ }^{40}$ The information collected provides relevant insight into real-life clinical practice, and it might serve to highlight areas of controversy, provide a basis to design research and policies and stimulate scientific collaboration to achieve the common goal of effective and safe pharmacotherapy in HF children.

\section{Author affiliations}

${ }^{1}$ Institute of Clinical Pharmacy and Pharmacotherapy, Heinrich-Heine-University Düsseldorf, Düsseldorf, Germany

${ }^{2}$ Mathematical Institute, Heinrich-Heine-University Düsseldorf, Düsseldorf, Germany ${ }^{3}$ Department of Paediatric Cardiology, Erasmus MC Sophia Children's Hospital, Rotterdam, The Netherlands

${ }^{4}$ Department of Paediatric Cardiology, University Children's Hospital, Belgrade, Serbia

${ }^{5}$ Department of Paediatric Cardiology, Medical University of Vienna, Vienna, Austria ${ }^{6}$ Department of Clinical Pharmacology, University Children's Hospital, Belgrade, Serbia

${ }^{7}$ Department of Pharmacology, Clinical Pharmacology and Toxicology, School of Medicine, University of Belgrade, Belgrade, Serbia

${ }^{8}$ Department of Pharmacology and Toxicology, Radboud University, Nijmegen, The Netherlands

${ }^{9}$ Intensive Care and Department of Paediatric Surgery, Erasmus MC Sophia Children's Hospital, Rotterdam, The Netherlands

${ }^{10}$ Göttsegen György Hungarian Institute of Cardiology, Paediatric Heart Centre, Budapest, Hungary

${ }^{11}$ Pharmaplex bvba, Wezembeek-Oppem, Belgium

${ }^{12}$ Jenny Walsh Consulting Ltd, BioCity Nottingham, UK

Acknowledgements We would like to thank all the physicians who voluntarily participated in this survey, making the completion of this study possible; also, to all the members of the expert panel for their input and support during the development of the survey tool. Our gratitude to Dr Anne van Hecken, University Hospital Leuven, who contributed to the identification of paediatric cardiology centres in Belgium, to Professor Michael Burch, Great Ormond Street Hospital, who contributed to the identification of paediatric cardiology centres in the UK and whose input served to support the questionnaire development and to Professor Jörg Breitkreutz, Heinrich-Heine-University Düsseldorf, for reviewing questions on ACE-I formulations. The results presented in this article are part of the PhD work of Ms Castro Díez, carried out at the Heinrich-Heine-University of Düsseldorf.

Contributors SL conceived the research idea. CCD, SL, IK, AS, LA, MB, AH, MD, SNW, MM, IJ, MB and CM contributed to the conception of the study. CCD, FK and HS contributed to the study design. CCD performed the experimental part. CCD, FK, NM and HS contributed to the analysis of data. CCD, FK, NM, SL, IK, LA, MD, SNW, $\mathrm{IJ}, \mathrm{MB}$ and $\mathrm{CM}$ contributed to the interpretation of the study results. CCD and SL elaborated the study report. CCD drafted the manuscript. FK, HS, MD, IJ, SNW, IK, $\mathrm{CM}$, JW and SL critically reviewed the manuscript. All authors approved the final version to be submitted for publication.

Funding The research leading to these results has received funding from the European Union Seventh Framework Programme (FP7/2007-2013) under grant agreement $n^{\circ} 602295$ (LENA). The aim of the European grant funded 'Labeling of Enalapril from Neonates to Adolescents' (LENA) project is to develop a safe, effective and age appropriate formulation of enalapril, for the treatment of heart failure in patients aged from birth to 18 years (https://www.lena-med.eu).

Competing interests All authors report grants from European Union Seventh Framework Programme during the conduct of the study.

Patient consent for publication Not required.

Ethics approval Ethics Committee of the Heinrich-Heine-University Düsseldorf.

Provenance and peer review Not commissioned; externally peer reviewed.

Data sharing statement The data can be open for sharing if required.

Open access This is an open access article distributed in accordance with the Creative Commons Attribution Non Commercial (CC BY-NC 4.0) license, which permits others to distribute, remix, adapt, build upon this work non-commercially, and license their derivative works on different terms, provided the original work is properly cited, appropriate credit is given, any changes made indicated, and the use is non-commercial. See: http://creativecommons.org/licenses/by-nc/4.0/.

\section{REFERENCES}

1. Hsu DT, Pearson GD, Hsu PGD. Heart failure in children: part I: history, etiology, and pathophysiology. Circ Heart Fail 2009;2:63-70.

2. Sommers $\mathrm{C}$, Nagel $\mathrm{BH}$, Neudorf $\mathrm{U}$, et al. [Congestive heart failure in childhood. An epidemiologic study]. Herz 2005;30:652-62.

3. Massin MM, Astadicko I, Dessy H. Epidemiology of heart failure in a tertiary pediatric center. Clin Cardiol 2008;31:388-91.

4. Rossano JW, Kim JJ, Decker JA, et al. Prevalence, morbidity, and mortality of heart failure-related hospitalizations in children in the United States: a population-based study. J Card Fail 2012;18:459-70.

5. Rossano JW, Dipchand AI, Edwards LB, et al. The registry of the international society for heart and lung transplantation: nineteenth pediatric heart transplantation report-2016; focus theme: primary diagnostic indications for transplant. J Heart Lung Transplantation 2016;35:1185-95.

6. Rossano JW, Shaddy RE. Heart failure in children: etiology and treatment. J Pediatr 2014;165:228-33.

7. Ponikowski P, Voors AA, Anker SD, et al. ESC Guidelines for the diagnosis and treatment of acute and chronic heart failure: The Task Force for the diagnosis and treatment of acute and chronic heart failure of the European Society of Cardiology (ESC)Developed with the special contribution of the Heart Failure Association (HFA) of the ESC. Eur Heart J 2016;2016:2129-200.

8. Yancy CW, Jessup M, Bozkurt B, et al. ACCF/AHA guideline for the management of heart failure: executive summary: a report of the American College of Cardiology Foundation/American Heart Association Task Force on practice guidelines. Circulation 2013:2013:1810-52.

9. Hsu DT, Zak V, Mahony L, et al. Enalapril in infants with single ventricle: results of a multicenter randomized trial. Circulation 2010;122:333-40.

10. Shaddy RE, Boucek MM, Hsu DT, et al. Carvedilol for children and adolescents with heart failure: a randomized controlled trial. JAMA 2007:298:1171-9. 
11. Kantor PF, Lougheed J, Dancea A, et al. Presentation, diagnosis, and medical management of heart failure in children: Canadian cardiovascular society guidelines. Can J Cardiol 2013;29:1535-52.

12. Kirk R, Dipchand Al, Rosenthal DN, et al. The international society for heart and lung transplantation guidelines for the management of pediatric heart failure: executive summary. $J$ Heart Lung Transplant 2014;33:888-909.

13. Taketomo C, Hodding J, Kraus D. Pediatric \& neonatal dosage handbook. 23rd edm. Hudson, Ohio: Lexi-Comp, Inc, 2016.

14. EMEA. Evidence of harm from off-label or unlicensed medicines in children. 2004 http://www.ema.europa.eu/docs/en_GB/document library/Other/2009/10/WC500004021.pdf

15. Andres L. Designing \& doing survey research. 1st edn. London: SAGE, 2012.

16. Burns KE, Duffett $M$, Kho ME, et al. A guide for the design and conduct of self-administered surveys of clinicians. CMAJ 2008;179:245-52.

17. Draugalis JR, Coons SJ, Plaza CM. Best practices for survey research reports: a synopsis for authors and reviewers. Am J Pharm Educ 2008;72:11.

18. Vogt W, Läer S. Prevention for pediatric low cardiac output syndrome: results from the European survey EuLoCOS-Paed. Pediatric Anesthesia 2011;21:1176-84.

19. Bengur AR, Beekman RH, Rocchini AP, et al. Acute hemodynamic effects of captopril in children with a congestive or restrictive cardiomyopathy. Circulation 1991;83:523-7.

20. Stern H, Weil J, Genz T, et al. Captopril in children with dilated cardiomyopathy: acute and long-term effects in a prospective study of hemodynamic and hormonal effects. Pediatr Cardiol 1990;11:22-8.

21. Lewis $A B$, Chabot $M$. The effect of treatment with angiotensinconverting enzyme inhibitors on survival of pediatric patients with dilated cardiomyopathy. Pediatr Cardiol 1993;14:9-12.

22. Kantor PF, Abraham JR, Dipchand Al, et al. The impact of changing medical therapy on transplantation-free survival in pediatric dilated cardiomyopathy. J Am Coll Cardiol 2010;55:1377-84.

23. Hsu DT, Pearson GD. Heart failure in children: part II: diagnosis, treatment, and future directions. Circ Heart Fail 2009;2:490-8.

24. Mori Y, Nakazawa M, Tomimatsu H, et al. Long-term effect of angiotensin-converting enzyme inhibitor in volume overloaded heart during growth: a controlled pilot study. J Am Coll Cardiol 2000;36:270-5.

25. Momma K. ACE inhibitors in pediatric patients with heart failure. Paediatr Drugs 2006;8:55-69.

26. Zak V, Hsu DT, Pemberton VL, et al. Translating clinical trials into clinical practice: a survey assessing the potential impact of the Pediatric Heart Network Infant Single Ventricle Trial. Cardiol Young 2017;27:1265-70

27. Paediatric Formulary Committee. BNF for children (BNFC) 20172018. 1st edn. London: BMJ Group and Pharmaceutical Press, 2017.

28. Leversha AM, Wilson NJ, Clarkson PM, et al. Efficacy and dosage of enalapril in congenital and acquired heart disease. Arch Dis Child 1994;70:35-9.
29. Packer M, Poole-Wilson PA, Armstrong PW, et al. Comparative effects of low and high doses of the angiotensin-converting enzyme inhibitor, lisinopril, on morbidity and mortality in chronic heart failure. ATLAS Study Group. Circulation 1999;100:2312-8.

30. López-Sendón J, Swedberg K, McMurray J, et al. Expert consensus document on angiotensin converting enzyme inhibitors in cardiovascular disease. The Task Force on ACE-inhibitors of the European Society of Cardiology. Eur Heart J 2004;25:1454-70.

31. Ross RD. The Ross classification for heart failure in children after 25 years: a review and an age-stratified revision. Pediatr Cardiol 2012;33:1295-300.

32. van der Meulen M, Dalinghaus M, Burch M, et al. Question 1: How safe are ACE inhibitors for heart failure in children? Arch Dis Child 2018:103:106.1-9.

33. Mulla $\mathrm{H}$, Tofeig M, Bu'Lock $\mathrm{F}$, et al. Variations in captopril formulations used to treat children with heart failure: a survey in the United kingdom. Arch Dis Child 2007;92:409-11.

34. Pabari RM, McDermott C, Barlow J, et al. Stability of an alternative extemporaneous captopril fast-dispersing tablet formulation versus an extemporaneous oral liquid formulation. Clin Ther 2012;34:2221-9.

35. Terano $\mathrm{C}$, Ishikura $\mathrm{K}$, Miura $\mathrm{M}$, et al. Incidence of and risk factors for severe acute kidney injury in children with heart failure treated with renin-angiotensin system inhibitors. Eur J Pediatr 2016;175:631-7.

36. Alabed S, Sabouni A, Al Dakhoul S, et al. Beta-blockers for congestive heart failure in children. Cochrane Database Syst Rev 2016:CD007037.

37. Lipshultz SE, Sleeper LA, Towbin JA, et al. The incidence of pediatric cardiomyopathy in two regions of the United States. N Engl J Med 2003;348:1647-55

38. Nugent AW, Daubeney PE, Chondros P, et al. The epidemiology of childhood cardiomyopathy in Australia. N Engl $J$ Med 2003;348:1639-46.

39. Adams AS, Soumerai SB, Lomas J, et al. Evidence of self-report bias in assessing adherence to guidelines. Int $J$ Qual Health Care 1999:11:187-92.

40. Li JS, Colan SD, Sleeper LA, et al. Lessons learned from a pediatric clinical trial: the pediatric heart network angiotensin-converting enzyme inhibition in mitral regurgitation study. Am Heart $J$ 2011;161:233-40.

41. United Nations Standard country or area codes for statistical use (M49). https://unstats.un.org/unsd/methodology/m49/ (Aaccesed Apr 2018).

42. European Medicines Agency. CPMP/ICH/2711/99 ICH Topic E 11 Clinical investigation of medicinal products in the paediatric population. http://www.ema.europa.eu/docs/en_GB/document library/Scientific_guideline/2009/09/WC500002926.pdf (Accessed Feb 2014).

43. Kidney Disease: Improving Global Outcomes (KDIGO) Acute Kidney Injury Work Group. KDIGO Clinical practice guideline for acute kidney injury. Kidney inter 2012;2:1-138. 